\title{
Potencial produtivo e precocidade de linhagens de amendoim em Ribeirão Preto na safra 2019/2020
}

$\begin{aligned} & \text { Submetido - } 08 \text { jul. } 2020 \quad \text { Aprovado - } 07 \text { ago. } 2020 \quad \text { Publicado - } 14 \text { out. } 2020 \\ & \text { dol }{ }_{\text {http://dx.doi.org/10.17648/sas.v1i2.26 }}\end{aligned}$

Andrea Rocha Almeida de Moraes (D)

Pesquisadora Científica do Instituto Agronômico de Campinas - IAC, Campinas - SP, e-mail: andrea@iac.sp.gov.br.

Olavo Betiol(iD

Pós-graduando, Universidade Estadual Paulista - UNESP/FCAV, Jaboticabal - SP, e-mail: olavobetiol96@gmail.com.

Pesquisador Científica do Instituto Agronômico de Campinas - IAC,, Centro Avançado de Pesquisa em Cana, Ribeirão Preto, SP, e-mail: denizart@iac.sp.gov.br.

João Francisco dos Santos ${ }^{(\mathbb{D}}$

Pesquisador Científica do Instituto Agronômico de Campinas - IAC, Campinas - SP, e-mail: joaofsantos@iac.sp.gov.br.

Pesquisador Científica do Instituto Agronômico de Campinas - IAC, Campinas - SP, e-mail: ijgodoy@iac.sp.gov.br.

\section{RESUMO}

O estudo teve como objetivo avaliar a produtividade e o grau de maturação de vagens, em linhagens de amendoim rasteiro, para selecionar cultivares com ciclo reduzido. $A$ avaliação da maturação foi realizada em duas datas de amostragem antes da colheita. $O$ experimento foi conduzido no município de Ribeirão Preto, SP, Brasil, em blocos ao acaso, utilizando-se dez linhagens e duas cultivares controles, com os genótipos sendo avaliados aos 119 e 125 dias após a semeadura. Em cada uma das épocas de avaliação, colheram-se amostras de 0,5 $m$ de plantas por linha, para se obter a maturação das vagens com base na tabela de classificação de coloração de maturação de vagens, variando de classe branca a classe preta. Aos 125 DAS realizou-se a colheita total de uma linha das parcelas dos genótipos, para obtenção da produtividade. Realizaram-se também avaliações de porcentagem do número de vagens maduras aos 119 e 125 DAS e porcentagem do ganho no número de vagens maduras do DAS 119 para 125. Com base nos resultados obtidos, pode-se concluir que a linhagem 13.24 apresentou a maior produtividade $\left(7.625 \mathrm{~kg} \mathrm{ha}^{-1}\right)$ entre as linhagens avaliadas. A linhagem 13.34 apresentou a maior valor em porcentagem de vagens maduras formadas aos 119 DAS (56,1\%). Os maiores acréscimos de porcentagem de ganho no número de vagens maduras em uma semana de plantio foram verificados nas linhagens 13.15 e 13.24. E há linhagens promissoras que serão avaliadas em mais ambientes visando à obtenção de cultivares produtivas de ciclo curto.

Palavras-chave: Arachis hypogaea L.; Maturação de vagens; Colheita antecipada.

\section{Productive potential and earliness of peanut lines in Ribeirao Preto - 2019/2020 growing season}

\author{
ABSTRACT
}

The objective of this study was to evaluate yield and pod maturity condition in peanut lines of the runner type, so as to indicate cultivars with reduced cycle. Maturity assesment was evaluated in two sampling dates before harvesting. The experiment was carried out in 
Ribeirão Preto, SP, Brasil, in randomized blocks design, testing tem breeding lines and two control cultivars. Pod maturity was evaluated at 119 and 125 days after planting. In each sampling date the plants contained in $0,5 \mathrm{~m}$ of row were collected and pod maturity was determined based in a maturity table considering the color of the pod mesocarp, in a scale varying from white to black. Harvesting to evaluate yield was done at 125 days after planting, by digging one of the two lines of each plot. Along with pod yield, the following variables were obtained: percentage of the number of mature pods in each sampling date and the percentage of increase in mature pods from the 119 to 125 sampling dates. The results indicated that, when harvesting at 125 days, the line 13.24 as the most productive $\left(7,625 \mathrm{~kg} \mathrm{ha}^{-1}\right)$. At 119 days after planting, the line 13.34 showed the highest percentage of mature pods $(56.1 \%)$. The lines 13.15 and 13.24 showed the largest increases in number of mature pods from the 119th to the 125 th day after planting. The results indicate that there are promising lines for selection as new cultivars combining productivity and earliness, to be confirmed in other environments.

Keywords: Arachis hypogaea L.; Pod maturity; Short cycle.

\title{
Potencial productivo y precocidad de líneas de maní en Ribeirão Preto en el cultivo de 2019/20
}

\author{
RESUMEN
}

El objetivo del estúdio fue evaluar el rendimento y madurez de vainas em líneas de maní rastrero, para selecionar cultivares com ciclo reducido. La madurez fue evaluada endos datas de muestreo antes de la cosecha. El experimento fue realizado en Ribeirão Preto, SP, Brasil, em bloques completamente al azar. Se estúdio diez líneas y dos cultivares controles, siendo la madurez evaluada a los 119 y 125 dias después de la siembra (DDS). En cada época de evaluación, se colletaron muestras de plantas en 0,5m lineales, para obtener la maduración de lãs vainas basada em la tabla de calificación de color de vainas maduras, variando de classe blanca a negra. A los 125 DDS se cosecharon todas las plantas de uma línea por parcela, para obtención del rendimento de los genótipos. Se evaluó también el porcentaje de vainas maduras desde los 119 y 125 DDS y el porcentaje de incremento em el número de vainas maduras desde los 119 hasta los 125 DDS. De acurdo com los resultados, la línea 13.24 tuvo el máximo rendimento (7.625 $\mathrm{kg} \mathrm{ha}^{-1}$ ) de todas las líneas evaluadas. Asi mismo, dicha línea presentó el máximo porcentaje de vainas maduras a los 119 DDS (56,1\%). Los maiores incrementos em porcentaje del número de vainas maduras em uma semana fueron verificados em las líneas 13.15 y 13.24. Los resultados indican que existem líneas promissórias para selección como nuevos cultivares, productivos y de ciclo corto, se recomiendan do evaluar estas líneas em otros ambientes.

Palabras claves: Arachis hypogaea L.; Maduración de vainas, Ciclo corto.

\section{Introdução}

O Estado de São Paulo se destaca como o maior produtor brasileiro de amendoim, com aproximadamente $92 \%$ de toda a oferta nacional (CONAB, 2019), onde grande parte do amendoim plantado é cultivado por produtores arrendatários em áreas de canaviais, no interstício de tempo antes que ocorra um novo plantio decana de açúcar.

As cultivares mais desejadas atualmente no mercado pertencem ao grupo morfológico Virginia, apresentando cultivares tipo "runner" alto oleico, 
de alto desempenho produtivo, e plantas cujo ciclo para plena maturação pode atingir de 130 a 150 dias.

Para que a cultura de amendoim se expanda cada vez mais dentro do estado de São Paulo, faz-se necessário adequar o período de ocupação das áreas de produção de amendoim durante a safra das águas com o calendário de plantio das novas áreas de canaviais (GODOY et al., 2017). Assim, nas condições de São Paulo, para que isso ocorra as cultivares devem ter ciclo de no máximo 130 dias (GODOY et al., 2014).

A fase reprodutiva do amendoim compreende as etapas: início do florescimento (R1), formação dos ginóforos ou pegs (R2), formação de vagens (R3), vagens cheias (R4), formação das sementes (R5), sementes cheias (R6), início da maturação (R7), maturação para colheita (R8) e vagem acima do ponto de maturação (R9) (BOOTE, 1982).

A etapa de maturação das vagens de amendoim é complexa, pois a planta apresentar hábito de crescimento indeterminado, ou seja, uma planta apresenta ao mesmo tempo vagens em diferentes estádios de maturação (CARLEY et al., 2008). Dessa maneira, a colheita do amendoim é normalmente iniciada quando as vagens atingem a maturação fisiológica completa, o que segundo Faria Jr. (2007), é obtido quando $70 \%$ das vagens encontram-se no pontodos estádios $\mathrm{R} 7$ e R8.

Para o estudo e a obtenção de cultivares precoces normalmente faz-se a colheita das linhagens em uma época determinada, observando-se o grau de maturidade de cada genótipo nessa época (GODOY et al., 2005) e, selecionando posteriormente dentre essas linhagens, as mais produtivas que apresentem as características desejadas pelo mercado consumidor.

Desse modo, este trabalho teve por objetivo avaliar a produtividade e o grau de maturação das vagens de dez linhagens de amendoim tipo "runner" do programa de melhoramento genético de amendoim do Instituto Agronômico (IAC), em duas épocas de colheita, para as condições edafoclimáticas de Ribeirão Preto, SP, para selecionar cultivares com ciclo reduzido. 


\section{Material e métodos}

O experimento em campo foi realizado na localidade de Ribeirão Preto, SP (latitude 21ㅇ 15' 22' S longitude 48ㅇ 1' 58" W e altitude de 554 m), nas dependências do Centro Avançado de Pesquisa em Cana do IAC, na safra de 2019/2020.

O delineamento experimental utilizado foi de blocos ao acaso, com quatro repetições, com as parcelas constituídas de duas linhas de 5 metros de comprimento e 0,9 metros de espaçamento entre linhas, semeando-se 100 sementes por linha. A semeadura foi realizada (05/11/2019) em área corrigida com calcário, tendo-se efetuado, em todos os experimentos, adubação com $300 \mathrm{~kg} \mathrm{ha}^{-1}$ de NPK da fórmula 4-30-10.

Todos os tratos culturais e fitossanitários foram feitos conforme recomendações técnicas para a cultura do amendoim (GODOY et al., 2005). Foram avaliadas dez linhagens de amendoim (13.10, 13.15, 13.19, $13.24,13.29,13.31,13.34,13.35,13.38,13.43)$ e, como controle, as cultivares IAC OL3 e Runner IAC 886, de ciclos conhecidos de 130 dias.

Uma linha de plantio de cada genótipo foi utilizada para realização das avaliações de vagens e a outra linha foi utilizada para obtenção da produtividade final da parcela aos 125 dias após a semeadura (DAS). As avaliações para vagem foram realizadas aos 119 (02/02/2020) e 125 (09/02/2020) dias após a semeadura.

Após as colheitas, as vagens foram lavadas com jato d'água sob pressão para expor a coloração do mesocarpo da vagem, o chamado método "hullscrape" (WILLIAMS e DREXLER, 1981), que consiste na raspagem do exocarpo da vagem, expondo a coloração do mesmo, para posterior comparação com a coloração da tabela de classificação de coloração de maturação de vagens (Profile Board), desenvolvido pela Universidade da Georgia, USA, onde: a classe de classificação preta seria o ponto máximo de maturação (vagem acima do ponto de maturação - R9); classe marrom identifica vagens maduras (maturação para colheita - R8); classe laranja, vagens próximas à maturidade (início da maturação - R7); 
classe amarela maturação intermediária (sementes cheias - R6), e; classe branca, as vagens imaturas (formação das sementes - $\mathrm{R} 5$ a vagens cheias - R4) (WILLIAMS e DREXLER, 1981; BOOTE, 1982).

Desse modo, após a separação e classificação, contou-se 0 número de vagens em cada classe de cor e, foram descartados os "pegs" e vagens em início de desenvolvimento (R2 e R3). Aos 125 DAS realizou-se a colheita de uma linha de 5 metros de cada linhagem. Essas plantas foram separadas manualmente e suas vagens secas naturalmente em terreiro ao sol, para posterior estimativa de sua produtividade em $\mathrm{kg} \mathrm{ha}^{-1}$.

Com os dados coletados, pôde-se obter também a porcentagem do número de vagens maduras aos 119 e 125 DAS e a porcentagem do ganho no número de vagens maduras do DAS 119 para 125. Para a obtenção desses dados, utilizou-se a soma das vagens classificadas como preta e marrom (R9 e R8) na escala da tabela de classificação de coloração de maturação de vagens.

Os resultados obtidos foram submetidos às análises da variância sendo as médias comparadas entre si pelo Teste de Tukey a $5 \%$ de probabilidade, com o uso do Programa Estatístico Genes (CRUZ, 2013).

\section{Resultados e discussão}

De acordo com a análise de variância detectou-se interação significativa entre os genótipos para a variável produtividade, indicando que as cultivares se comportaram de maneira distinta entre si nas mesmas condições de cultivo em campo.

A linhagem 13.24 apresentou o maior valor $\left(7.625 \mathrm{~kg} \mathrm{ha}^{-1}\right)$ entre as linhagens avaliadas, diferindo estatisticamente apenas das linhagens 13.31, 13.35 e 13.43 para produtividade (Tabela 1), mas não diferindo das cultivares IAC.

A produtividade dos genótipos variou entre $5.567 \mathrm{~kg} \mathrm{ha}^{-1}$ e $7.625 \mathrm{~kg}$ $\mathrm{ha}^{-1}$, com as cultivares controles Runner IAC 886 e IAC OL3 produzindo 
$6.460 \mathrm{~kg} \mathrm{ha}^{-1}$ e $5.969 \mathrm{~kg} \mathrm{ha}^{-1}$, respectivamente, não deferindo em produtividade de nenhuma das linhagens avaliadas nesse experimento (Tabela 1).

Tabela 1. Produtividade média $\left(\mathrm{kg} \mathrm{ha}^{-1}\right)$ de linhagens de amendoim colhidas antecipadamente em Ribeirão Preto, SP, na safra de 2019/2020.

\begin{tabular}{ll}
\hline & Média \\
& \\
\hline 13.24 & $7.625 \mathrm{a}$ \\
13.38 & $6.941 \mathrm{ab}$ \\
13.19 & $6.566 \mathrm{ab}$ \\
Runner IAC 886 & $6.460 \mathrm{ab}$ \\
13.29 & $6.449 \mathrm{ab}$ \\
13.34 & $6.155 \mathrm{ab}$ \\
IAC OL3 & $5.969 \mathrm{ab}$ \\
13.10 & $5.850 \mathrm{ab}$ \\
13.15 & $5.778 \mathrm{ab}$ \\
13.31 & $5.617 \mathrm{~b}$ \\
13.35 & $5.611 \mathrm{~b}$ \\
13.43 & $5.567 \mathrm{~b}$ \\
\hline Média & $\mathbf{6 . 2 1 6}$ \\
CV (\%) & $\mathbf{1 8 , 0 6}$ \\
DMS & $\mathbf{2 . 0 0 6}$ \\
\hline
\end{tabular}

(1)DMS: Diferença mínima significativa entre médias com base no teste Tukey, a 5\% de probabilidade.

Verificou-se que todas as linhagens apresentaram potencial produtivo acima de $5.500 \mathrm{~kg} \mathrm{ha}^{-1}$. O mesmo potencial produtivo foi verificado por Mendes et al. (2018) ao realizar avaliação do grau de maturação das vagens de genótipos de amendoim também visando colheita antecipada utilizando linhagens selecionadas pelo IAC.

Segundo Godoy et al. (2005), para a obtenção de cultivares precoces faz-se a colheita das linhagens em uma época determinada, observando-se o grau de maturidade de cada genótipo nessa época. Desse modo, nesse estudo, fez-se a colheita dos genótipos aos 125 DAS visando observar a produtividade e o comportamento das linhagens em colheita precoce.

Os dados mostram que as linhagens avaliadas apresentam uma boa granação e bom desempenho produtivo quando colhidas aos 125 dias 
após a semeadura, visto que não diferiram estatisticamente das principais cultivares IAC utilizadas como padrão. Ou seja, a seleção visando linhagens produtivas com ciclo mais curto, se mostrou estar sendo bem sucedida.

Segundo Rucker et al. (1994), para se determinar o ciclo de uma cultivar faz-se normalmente avaliação do grau de maturidade das vagens e de formação dos grãos. Esta observação pode ser feita visualmente pela maior porcentagem do número de vagens maduras na planta. Seguindo essa metodologia, foram feitas avaliações de maturação de vagens aos 119 e 125 dias após a semeadura dos genótipos.

Assim, avaliando-se a porcentagem do número de vagens maduras de linhagens de amendoim colhidas antecipadamente aos 119 e 125 DAS, não ocorreu diferença significativa entre as linhagens (Figura 1).

Aos 119 dias após a semeadura, verificou-se que os valores variaram de $34,7 \%$ (linhagem 13.38) a $56,1 \%$ (linhagem 13.34) na quantidade de vagens que já estavam maduras nessa primeira época de avaliação (Figura 1).

Nessa mesma avaliação, as cultivares usadas como controles apresentaram 44,6\% (Runner IAC 886) e 38,3\% (IAC OL3) de vagens maduras e a linhagem 13.34, atingiu o maior valor $(56,1 \%)$ de vagens já plenamente formadas e maduras.

Na segunda avaliação de número de vagens maduras (125 DAS), as linhagens $13.10,13.24$ e 13.34 foram as que apresentaram os maiores valores, bem próximo ao obtido pela Runner IAC 886 (Figura 1).

Como a colheita e o ciclo de uma cultivar é determinada pela maior porcentagem do número de vagens maduras na planta (estádio R7 e R8) (FARIA JR., 2007), infere-se que essas linhagens apresentam potencial de ciclo vegetativo precoce. 


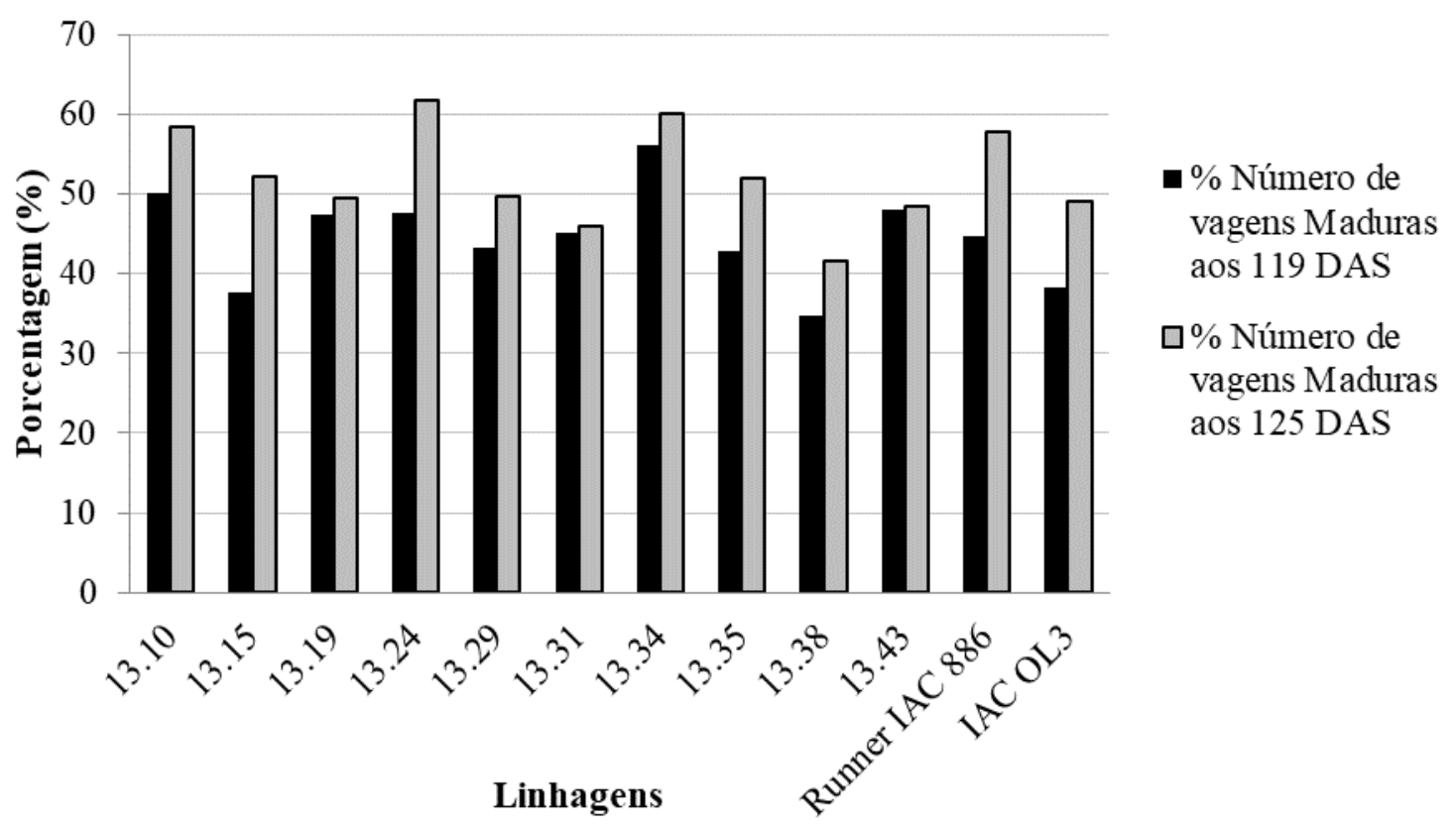

Figura 1. Porcentagem do número de vagens maduras de linhagens de amendoim colhidas antecipadamente em Ribeirão Preto, SP, na safra de 2019/2020.

Quando se analisou o ganho em porcentagem de número de vagens maduras de uma semana para outra (do 119 DAS para o 125 DAS), verificou-se que houve variação em termos de maturação de vagens entre as linhagens e as duas épocas de avaliação de maturação (Figura 2).

As linhagens 13.15 e 13.24, assim como a cultivar Runner IAC 886 apresentam os maiores valores de ganho, em torno de $14,5 \%, 14,0 \%$ e 13,2\%, respectivamente (Figura 2).

Enquanto três linhagens apresentaram baixos índices de porcentagem do ganho em número de vagens maduros do119 DAS para 125 DAS, como no caso das linhagens 13.19 (2,0\% de ganho), 13,31 $(0,9 \%)$ e $13.43(0,4 \%)$ (Figura 2$)$.

Esses dados apontam que há linhagens bem promissoras e produtivas quando colhidas em ciclo determinado e reduzido, mas sendo necessário mais estudo, em maior número de ambientes, para uma melhor definição dos potenciais dessas linhagens. 


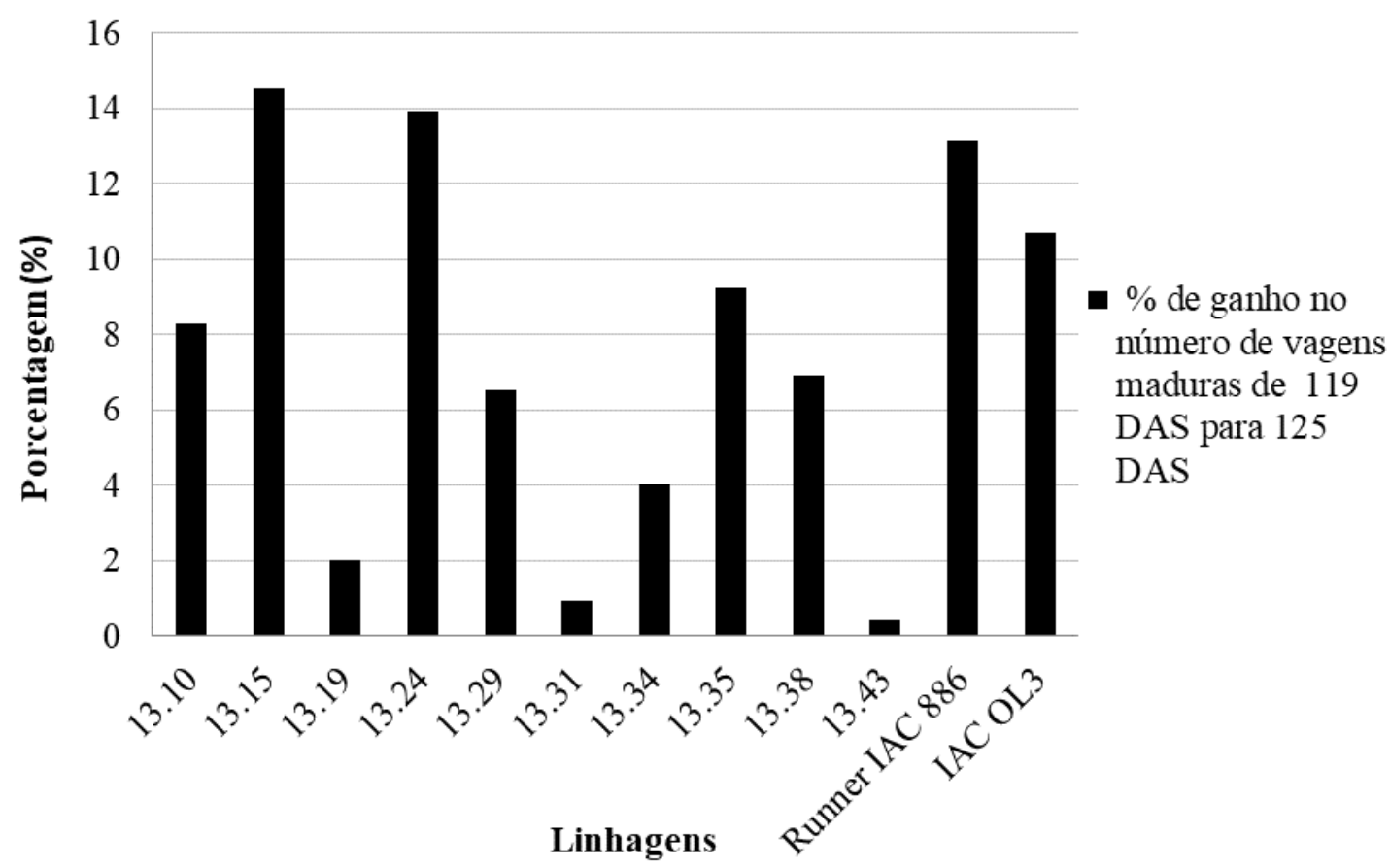

Figura 2. Porcentagem do ganho em número de vagens maduras dos 119 DAS para 125 DAS, em linhagens de amendoim colhidas antecipadamente em Ribeirão Preto, SP, na safra de 2019/2020.

\section{Conclusões}

A linhagem 13.24 apresentou a maior produtividade $\left(7.625 \mathrm{~kg} \mathrm{ha}^{-1}\right)$ entre as linhagens avaliadas. A linhagem 13.34 apresentou o maior valor em porcentagem de vagens maduras formadas aos 119 DAS $(56,1 \%)$. Os maiores acréscimos de porcentagem de ganho no número de vagens maduras em uma semana de plantio foram verificados nas linhagens 13.15 e 13.24. Há linhagens promissoras que serão avaliadas em mais ambientes visando à obtenção de cultivares produtivas de ciclo curto. 


\section{Referências}

BOOTE, K. J. Growth stages of peanut (Arachis hypogaea L.). Peanut Science, v. 9, n. 1, p. 35-40, 1982.https://doi.org/10.3146/i0095-3679-9-111

CARLEY, D. S.; JORDAN, D. L.; DHARMASRI, L. C.; SUTTON, T. B.; BRANDENBURG, R. L.; BURTON, M. G. Response to planting date and potential of canopy reflectance as an indicator of pod maturation. Agronomy Journal, v. 100, n. 2, p. 376-380, 2008. https://doi.org/10.2134/agronj2006.0352

CONAB. Companhia Nacional de Abastecimento. Acompanhamento da Safra Brasileira. Disponível em: https://www.conab.gov.br/infoagro/safras/graos. Acesso em: 02 de junho de 2020.

CRUZ, C. D. GENES. A software package for analysis in experimental statistics and quantitative genetics. Acta Scientiarum, v.35, n.3, p.271-276, 2013. https://doi.org/10.4025/actasciagron.v35i3.21251.

FARIA JR., P. Perdas na colheita do amendoim. In: ENCONTRO SOBRE A CULTURA DO AMENDOIM, 4., 2007, Jaboticabal, SP. Palestras..., Jaboticabal: Funep, 2007. 1 CD-ROM.

GODOY, I.J.; SANTOS, J.F.; MICHELOTTO, M.D.; MORAES, A.R.A.; BOLONHEZI, D.; FREITAS, R.S.; CARVALHO, C.R.L.; FINOTO, E.L.; MARTINS, A.L.M. IAC OL5 - New high oleic runner peanut cultivar. Crop Breeding and Applied Biotechnology n. 17, p. 289-292, 2017. https://doi.org/10.1590/1984-70332017v17n3c45

GODOY, I.J.; BOLONHEZI, D.; MICHELOTTO, M.D.; FINOTO, E.L.; KASAI, F.S.; FREITAS, R.S. Amendoim Arachis hypogaea L. In: AGUIAR, A.T.E.; GONÇALVES, C.; PATERNIANI, M.E.A.G.Z.; TUCCI, M.L.S.; CASTRO, C.E.F. (Eds.). Instruções agrícolas para as principais culturas econômicas. 7ed., Campinas -SP, Instituto Agronômico, p. 22-27, 2014.

GODOY, I. J.; MORAES, S. A.; ZANOTTO, M. D.; SANTOS, R. C. Melhoramento do Amendoim. In: A. Borém (editor). (Org.). Melhoramento de Plantas: Culturas Agronômicas.2. ed., Viçosa, MG, 2005, 817p.

RUCKER, K. S.; KVIEN, C. C. K.; VELLIDIS, G.; HILL, N. S.; SHARPE, J. K. A visual method of determining maturity of shelled peanuts. Peanut Science, v. 21, p. 143-146, 1994.https://doi.org/10.3146/i0095-3679-21-216

WILLIAMS, E.J; DREXLER, J.S. A non-destructive method for determining peanut pod maturity. Peanut Science, v. 8, n. 2, p. 134-141, 1981.https://doi.org/10.3146/i0095-3679-8-2-15 
MENDES, C. M. F.; FERRAZ, M.; LIMA, I. A.; SOUZA, W. M.; GODOY, I. J.; MICHELOTTO, M. D. Avaliação do grau de maturação das vagens de genótipos de amendoim visando colheita antecipada. In: Anais do encontro sobre a cultura do amendoim, 2018, São Paulo. Anais eletrônicos... Campinas, Galoá, 2018. Disponível em: https://proceedings.science/encontro-amendoim-2018/papers/avaliacao-dograu-de-maturacao-das-vagens-de-genotipos-de-amendoim-visandocolheita-antecipada. Acesso em: 23 jun. 2020. 